\title{
Políticas de Accountability na gestão educacional do estado de Pernambuco - Brasil
}

\section{Accountability policies in the educational management of the state of Pernambuco - Brazil Políticas de Accountability en la gestión educativa del estado de Pernambuco - Brasil \\ PROCIANA FERREIRA DA SILVA EDNA GUSMÃO DE GÓIS BRENNAND}

Resumo: A pesquisa tem como objetivo analisar as estratégias de implantação do modelo de accountability implantadas no sistema de gestão da rede de ensino básico da Secretaria de Educação do Estado de Pernambuco - Brasil e se essa política favorece mecanismos de gestão democrática. O estudo é de natureza exploratória, realizado através da técnica de pesquisa documental. Os resultados apontam que o modelo de accountability implantado é constituído por mecanismos de controle e monitoramento alinhados à disputa entre países europeus e norteamericanos por lugares competitivos no mercado global.

Palavras-chave: Políticas educacionais. Democracia. Gestão. Accountability.

Abstract: This research aims to analyze the implementation strategies of the accountability model implemented in the system of management of the basic education network of the State of Pernambuco - Brazil Education Department, and if this policy favors mechanisms of democratic management. The study is exploratory in nature, carried out through the documentary research technique. The results indicate that the accountability model implemented consists of control and monitoring mechanisms aligned to the dispute between European and North American countries for competitive places in the global market.

Keywords: educational policies; democracy; management. accountability.

Resumen: La investigación tiene como objetivo analizar las estrategias de implementación del modelo de accountability implementado en el sistema de gestión de red de la escuela primaria de la Secretaría de Educación del Estado de Pernambuco - Brasil, y si esta política favorece a los mecanismos de gestión democrática. El estudio es de naturaleza exploratoria, realizado por la técnica de investigación documental. Los resultados muestran que el modelo de accountability implantado se constituye por mecanismos de control y supervisión junto a la disputa entre los países europeos y norteamericanos por lugares competitivos en el mercado mundial.

Palabras clave: políticas educativas. Democracia. Gestión. accountability. 


\section{INTRODUÇÃO}

Nas duas últimas décadas, os chamados Estados-Nações têm sido, sob diversos aspectos, questionados em função das políticas globais e das realidades internacionais emergentes. Para compreender a crise desses estados, é preciso desvendar as relações, os processos e as estruturas que transcendem o EstadoNação, desde os subalternos aos dominantes. A soberania do Estado-Nação, além de limitada, está, também, abalada em sua base, uma vez que o princípio da maximização da acumulação do capital enquanto modo de produção e processo civilizatório cria e recria o Estado-Nação, onde é o princípio da soberania que define sua essência no âmbito das configurações e movimentos da sociedade global.

Nesse contexto, a crise da democratização do Estado tornou-se tema central na teoria política contemporânea. $\mathrm{O}$ enfrentamento das contradições estruturais expressam-se na corrupção, no enfraquecimento da densidade eleitoral e no crescimento da violência e da pobreza. As contradições estruturais existentes nas formas de democracia contemporâneas fizeram surgir diferentes concepções de reformas do Estado. A literatura especializada sobre a crise do Estado-Nação apresenta, em seus debates, pontos de discordância quanto às características e nuances diferenciadas em várias regiões do planeta; entretanto, apresenta um ponto de interseção importante. A democratização do EstadoNação demanda o aprofundamento da compreensão de modelos de gestão. Entre muitos apresentados e amplamente utilizado em diversos setores do mercado está o modelo denominado accountability entendido como a necessidade do Estado de prestar contas de suas ações à sociedade, criando mecanismos democráticos de participação (BROOKE, 2006).

A utilização do modelo de accountability como resultado dos modelos democráticos chega também ao campo educacional, porquanto a disputa entre os países por lugares competitivos no mercado global levou os governos a se preocuparem com os resultados dos seus sistemas escolares. A necessidade de mais informações sobre esses resultados tem sido respondida pela implementação de políticas de accountability, ou seja, de responsabilização "mediante as quais se tornam públicas as informações sobre o trabalho das escolas e consideram-se os gestores e outros membros da equipe escolar como corresponsáveis pelo nível de desempenho alcançado pela instituição" (BROOKE, 2006).

As políticas de avaliações que têm marcado o campo da educação, em especial nas instituições educativas públicas, são construídas a partir do discurso de que compete ao Estado oferecer uma educação de boa qualidade acompanhada do controle social e da responsabilização. A institucionalização da avaliação como 
política de Estado resultou de um extenso processo de estudos e de experiências desenvolvidas tanto no Brasil quanto em outros países. Os primeiros estudos internacionais que visavam a estabelecer comparações entre os resultados obtidos por estudantes de diversos países submetidos a um mesmo teste foram desenvolvidos através do Programme for International Student Assessment (PISA) ${ }^{1}$ e coordenados pela Organização de Cooperação e de Desenvolvimento Econômico (OCDE) ${ }^{2}$ (HORTA NETO, 2007).

Assim, o artigo tem como objetivo analisar a experiência do modelo de accountability em Pernambuco para oferecer subsídios aos debates sobre modelos de gestão adequados à realidade da qualidade da escola brasileira. Registra, através de análise realizada em documentos oficiais a política educacional do estado. Sintetiza as estratégias de accountability implantadas na rede de ensino estadual de Pernambuco, e discute se esse modelo favorece mecanismos de gestão democrática que ampliem os espaços de participação e a institucionalização de experiências participativas e de empoderamento de todos os envolvidos no processo educativo.

\section{ASPECTOS METODOLÓGICOS DA PESQUISA}

O objetivo da pesquisa foi analisar se as estratégias de accountability implantadas no sistema de gestão da rede de ensino básico da Secretaria de Educação do Estado de Pernambuco-Brasil a partir do ano de 2007, e verificar se essas favoreceram mecanismos de gestão democrática, espaços de participação, experiências participativas e de empoderamento. O campo empírico foi constituído por Decretos, Leis, Boletins Técnicos, Cartilhas, Relatórios, Notas Técnicas e Programas publicados e acessíveis via internet, que sintetizam a Implantação da Política Estadual para a Educação Básica. A análise documental foi realizada tomando-se como matriz conceitual os mecanismos apontados pela literatura especializada sobre o modelo de accountability para verificar se os mesmos influenciaram o sistema de gestão de ensino das escolas da Educação Básica do estado de Pernambuco. O sistema é gerido pela Secretaria de Educação

\footnotetext{
1 O Programa Internacional de Avaliação de Alunos (PISA) é um estudo internacional trienal, cujo objetivo é avaliar os sistemas de educação em todo o mundo, para testar as habilidades e os conhecimentos dos alunos de 15 anos de idade. Até essa data, os estudantes, que representam mais de 70 economias, têm participado da avaliação. Os resultados mais recentes publicados são da avaliação de 2012 (OCDE, 2015a).

2 A Organização para a Cooperação e o Desenvolvimento Econômico (OCDE) é uma organização internacional, composta por 34 países (Austrália, Áustria, Bélgica, Canadá, Chile, República Checa, Dinamarca, Estônia, Finlândia, França, Alemanha, Grécia, Hungria, Islândia, Irlanda, Israel, Itália, Japão, Coreia, Luxemburgo, México, Holanda, Nova Zelândia, Noruega, Polônia, Portugal e República Eslovaca), com sede em Paris, na França (OCDE, 2015b).
} 
e Esporte desse Estado, que se subdivide em 16 Gerências Regionais de Educação - GREs - que aglutinam um grupo de escolas de determinada região geográfica do Estado.

\section{O BRASIL E A IMPLANTAÇÃO DE UM SISTEMA DE AVALIAÇÃO EM LARGA ESCALA}

A discussão em torno da implantação de um sistema de avaliação em larga escala no contexto brasileiro ocorreu, inicialmente, na reforma empreendida na década de 30 , sem mudanças significativas até a década de 80 . O discurso de que o Brasil necessitava de uma política de garantia de acesso e permanência e uma escola de boa qualidade foi anunciado na Constituinte de 1988, cujos artigos 206 e 209 associam a "garantia de um padrão de qualidade" da educação a um Sistema de Avaliação e que a avaliação da qualidade pelo poder público aparece como condição da concessão do ensino livre à iniciativa privada.

A partir de 1990, o Sistema Brasileiro de Avaliação da Educação Básica (SAEB) propõe um conjunto de avaliações em larga escala, desenvolvido visando a criar mecanismos para formular, reformular e monitorar as políticas públicas no sentido de contribuir para a melhora da qualidade do ensino brasileiro. Até o ano de 1993, o SAEB apresentou sob a forma de amostragem composta pelas escolas que ofertavam a $1^{\mathrm{a}}$, a $3^{\mathrm{a}}$, a $5^{\mathrm{a}}$ e a $7^{\mathrm{a}}$ séries do Ensino Fundamental das escolas públicas da rede urbana as avaliações em larga escala mais importantes. Os estudantes também foram avaliados em Língua Portuguesa, Matemática e Ciências, e a $5^{a}$ e a $7^{a}$ séries foram avaliadas em redação. A partir do ano de 1995, a metodologia de construção do teste e da análise de resultados mudou e passou a ter como aporte teórico a Teoria de Resposta ao Item (TRI) ${ }^{3}$, metodologia por meio da qual se podem comparar os resultados das avaliações ao longo do tempo (BRASIL, 2015b).

No ano de 2005, o SAEB passou por uma reestruturação, através da Portaria Ministerial no 931, de 21 de março de 2005, quando passou a comporse por duas avaliações: a Avaliação Nacional da Educação Básica (ANEB) e a Avaliação Nacional do Rendimento Escolar (ANRESC), conhecida como Prova Brasil. Em 2013, é criada a Avaliação Nacional da Alfabetização (ANA) através da Portaria no 482, de 7 de junho de 2013. A ANEB e a ANRESC - Prova Brasil - são realizadas bianualmente, enquanto a ANA, anualmente. A ANA é uma respondente. Essa relação é sempre expressa de tal forma que quanto maior a habilidade maior a probabilidade de acerto no item (Andrade; Tavares; Valle, 2000). 
avaliação "censitária, que envolve os alunos do $3^{\circ}$ ano do Ensino Fundamental das escolas públicas, com o objetivo principal de avaliar os níveis de alfabetização e de letramento em Língua Portuguesa, alfabetização matemática e as condições de oferta do Ciclo de Alfabetização das redes públicas”. Já em 2007, o Índice de Desenvolvimento da Educação Básica (IDEB), criado pelo Instituto Nacional de Estudos e Pesquisas Educacionais Anísio Teixeira (INEP), passa, também, a compor esse sistema de avaliação, com o objetivo de monitorar o andamento das políticas públicas pela análise combinada do desempenho dos alunos nos exames Prova Brasil e SAEB e das taxas de aprovação de cada escola (BRASIL, 2015a).

\section{A REFORMA EDUCACIONAL NO ESTADO DE PERNAMBUCO}

A globalização, como fenômeno multidimensional, obedece a decisões de natureza econômica e política, através das quais influencia direta ou indiretamente diversas nações. Sabe-se que a economia não se move mecanicamente, porque depende da complexa relação das forças políticas que se estruturam em âmbito internacional. Desse modo, alguns padrões e valores socioculturais característicos da ocidentalidade, principalmente a forma europeia e a norte-americana, passaram a influenciar as formas de sociedade em escala global. Isso expressa o vaivém do processo histórico-social da ocidentalização ou modernização do mundo. Ela está na base de muitos estudos, debates, prognósticos, práticas e ideais relativos à mundialização. As políticas de 'modernização' e 'racionalização', assim como as de 'desregulação', 'desestatização' e 'liberalização, preconizadas pelo Fundo Monetário Internacional- FMI e pelo Banco Interamericano de Desenvolvimento (BIRD, juntamente com as corporações transnacionais, em geral orientadas pelo neoliberalismo, podem criar condições de se realizar o excedente econômico. A expressão 'planejamento' nem sempre está explícita, mas as políticas e as diretrizes, ou os diagnósticos e os prognósticos das organizações multilaterais e das corporações, destinam-se a orientar e a disciplinar o uso de recursos, a modernização de instituições e a racionalização de mentalidades e de práticas, a fim de aperfeiçoar e dinamizar a produtividade e a lucratividade (IANNI, 2001).

No Brasil, essas reformas aconteceram por volta da década de 90 , com a finalidade de transformar a administração burocrática em gerencial. Segundo Bresser Pereira (2006b, p. 21-22), essa reforma teria o objetivo de possibilitar "uma administração pública moderna e eficiente, compatível com o capitalismo competitivo [e seria, portanto], necessário flexibilizar o estatuto da estabilidade dos servidores públicos de modo a aproximar os mercados de trabalho público e privado". Podemos dizer, grosso modo, que a globalização é "um processo civilizatório que invade todo o globo, envolve o intercâmbio universal e cria as 
bases de um novo mundo, influenciando, destruindo ou recriando outras formas sociais de trabalho e vida, outras formas culturais e civilizatórias" (IANNI, 2001, p. 201).o contexto das preconizadas reformas, no ano de 2006, o Ministério da Educação (MEC), através do Instituto Nacional de Estudos e Pesquisas Educacionais Anísio Teixeira (INEP), apresentou ao governo de Pernambuco o Índice de Desenvolvimento da Educação Básica (IDEB), segundo o qual o Estado estava com o pior índice, na $5^{\mathrm{a}}$ e na $8^{\mathrm{a}}$ séries, em relação aos demais estados brasileiros. Apresentava um alto percentual de defasagem idade-série, elevados índices de evasão e de repetência e altas taxas de analfabetismo. Na tentativa de corrigir esses índices, em 2007, é implantado um modelo de gestão de educação baseada em resultados e se desenvolvem diretrizes, estratégias e planos operativos nas áreas de Saúde, Segurança Pública e Educação. Na área da Educação, foi implantado o Programa de Modernização da Gestão: metas para a Educação PMGE-ME, apoiado pelo Instituto de Desenvolvimento Gerencial (INDG), órgão que presta consultoria à Gestão Empresarial no Brasil, que foi premiado pela Organização das Nações Unidas (ONU) Esse modelo de gestão tem como foco a política de responsabilização educacional, que estabelece responsabilidades no âmbito das escolas, das Gerências Regionais e da Secretaria de Educação. As estratégias de responsabilização se efetivam ao serem estabelecidas as metas anuais por escola, a partir do Índice de Desenvolvimento de Pernambuco (IDEP) e a implantação do bônus por desempenho educacional (BDE) (PERNAMBUCO, 2012a). O novo modelo gerencial em implantação requer mais responsabilidade dos serviços por parte dos gestores e, consequentemente, o uso de estratégias que envolvam mais participação dos cidadãos na cobrança por boa qualidade nos serviços públicos. Isso nos remete ao conceito de accountability que vem sendo amplamente utilizado na Inglaterra e nos Estados Unidos como forma de os cidadãos controlarem os serviços públicos (CASTRO, 2008).

Os documentos base sobre a reforma mostram claramente que a categoria 'reforma' se apresenta associada a 'melhoria'. Aparece relacionada à melhoria do processo

ensino-aprendizagem, a partir dos indicadores educacionais, acompanhado de um discurso de promoção da qualidade social da educação e quando vem associada a 'mudança', apresenta-se nos documentos vinculadas ao modelo de gestão implantado pelo Estado (PERNAMBUCO, 2002, 2007, 2008, 2011?, 2012d, 2013, 2014, 2015a?, 2015b?, 2015c?)

Foi possível perceber, que a reforma empreendida no campo educacional no estado de Pernambuco vem fortalecer o discurso empreendido na década de 90 e defendido, principalmente, por Bresser Pereira (2002, 2005, 2006a, 2006b, 2006c, 2013a, 2013b) de que o Estado deveria adequar-se ao contexto globalizado, 
do qual deveria adotar um modelo de gestão gerencial baseado na descentralização, no controle de resultados, na competição e no controle social. Isso é evidenciado nos documentos (PERNAMBUCO, 2008a, 2012d, 2013, 2014) onde fica explícito que o Estado entende a melhoria do processo de ensino-aprendizagem como o alcance de indicadores de resultados pré-estabelecidos, o planejamento voltado para a avaliação, o resultado, o monitoramento e o controle são característicos da abordagem administrativa gerencial, o que indica uma adequação do sistema educacional para o atendimento às demandas criadas pelo acirramento do capital.

Assim, ficam claros os sinais de que ocorreu e/ou está a ocorrer, a partir da implantação da "reforma" da gestão educacional em Pernambuco, uma modificação na orientação das tarefas do Estado e no reconhecimento de que a burocracia estatal está a caminhar para o modelo gerencial de gestão orientado para o atendimento dos cidadãos-clientes. Diante disso, coube-nos examinar a categoria 'Estado', visto que a reforma se deu na estrutura estatal visando a melhorar o serviço público, no caso aqui estudado. De acordo com Afonso (2009c)"o Estado não pode deixar de ser integrado como um elemento chave na análise das políticas educativas, [pois][...]o Estado e o modo como esse funciona não é condição indispensável para problematizar a função da escola e da educação” (p. 95-98), No exame dos documentos, a categoria 'Estado' aparece nos achados como forma organizacional, como entidade que tem poder soberano para governar um povo em uma área territorial delimitada. Neles, seu papel é apresentado como garantidor do bem-estar social. No entanto, todo o planejamento educacional pauta-se na eficiência e eficácia, com vistas às necessidades do mundo globalizado que são características do Estado Neoliberal.

Em 2007, o estado de Pernambuco vivia uma crise de racionalidade administrativa, evidenciada pelo fato de seu sistema de ensino encontrar-se com os piores resultados do IDEB no Brasil. Isso provocou um questionamento sobre a qualidade da escola pública pernambucana o que obrigou a redefinição dos propósitos da educação no Estado. É colocada em pauta uma 'modernização' do modelo de gestão educacional, apoiado, fundamentalmente, em estratégias administrativas, a fim de se expandir e reorganizar o sistema educativo, com a preocupação de elaborar uma política educacional voltada para o atendimento dos interesses econômicos, quando foi implantado um sistema de gerenciamento da educação que tem como base a avaliação, o monitoramento e a pactuação de metas.

A descrença no sistema educativo vivenciada naquele momento reflete a crise de legitimidade, que teve como foco o discurso de uma educação de boa qualidade social pontuada como acesso, permanência e formação plena do aluno e pautada nos princípios de inclusão e cidadania. Esse discurso veio na tentativa 
de restabelecer a legitimidade do Estado para atender aos propósitos pretendidos pela sociedade e as instituições educacionais. Desse modo, evidencia-se a crise de motivaşão anunciada por Habermas (1980), a qual tende a estimular mudanças nas políticas educativas e, sobretudo, as voltadas a introduzir formas de avaliar a partir de matrizes curriculares previamente estabelecidas nos sistemas de ensino. Essas avaliações são consideradas como forma de promover a motivação dos alunos e o desenvolvimento do Estado. Isso, mais uma vez, caracteriza a estreita ligação entre as reformas educacionais e os interesses econômicos internacionais, além de ser um equívoco o entendimento de que a motivação independe das discussões (legitimidade) sobre como os conteúdos estudados podem promover a aprendizagem significativa para o aluno.

É nesse contexto que surge o Estado-avaliador que, segundo Afonso (2001, 2009c, 2012), expressa o ethos competitivo que admite a lógica de mercado, através da importação do modelo de gestão do setor privado que dá ênfase a resultados. Assim, a avaliação aparece como pré-requisito para a implantação desses mecanismos de gestão. Isso se justifica porque, conforme estamos vivenciando no acompanhamento dos níveis da educação nacional, é necessário criar e manter altos padrões de inovação científica e tecnológica para enfrentar a competitividade internacional e estabelecer objetivos claros e bem definidos por meio dos quais se possam medir os indicadores e as performances dos sistemas educacionais. Como se verifica nessas argumentações, as crises educacionais e, consequentemente, as reformas educacionais para sanar essa crise, mantêm ligação direta com as condições e as consequências do funcionamento do sistema econômico.

\section{O MODELO DE ACCOUNTABILITY NO SISTEMA EDUCACIONAL DE PERNAMBUCO}

A análise documental permitiu perceber que os objetivos educacionais propostos para o estado de Pernambuco, foram traçados para desenvolver atividades, com o fim de formar cidadãos capazes de responder às necessidades do sistema econômico, distanciando-se de sua função primordial que é a de formar sujeitos autodeterminados. A escola se constitui em um espaço de construção dos saberes capazes de contribuir para a democratização da sociedade. A realidade vivida por seus integrantes deve ser exposta à crítica, para que, através de argumentações fundamentadas, deem significado ao papel da educação na formação de sujeitos críticos e argumentativamente competentes. Ações elaboradas a partir do entendimento e do consenso podem transformar a escola em um espaço competente na formação de sujeitos autônomos e socialmente 
responsáveis. Para isso, é imprescindível que sejam construídas práticas de gestão articuladas pelo entendimento e pelo consenso, a fim de promover um ambiente favorável à participação e à democratização. Com base nesse pensamento, foi oportuno analisar a categoria 'gestão', no sentido de se compreender o modelo implantado. $\mathrm{Na}$ exploração dos documentos base, constatamos que o sistema educacional de Pernambuco adota o modelo de gestão por resultados, tendo como base o "planejamento estratégico, a responsabilização e o monitoramento - controle” (PERNAMBUCO, 2002, 2007, 2008a, 2012d, 2013, 2014) Não há evidências claras de que esse modelo tenha sido debatido nem com a população nem com atores escolares. O Estado ainda entende que a cultura democrática e de participação pode ser consolidada a partir de diagnóstico, planejamento e gestão. Nesse sentido, Habermas (1997b) assevera que somente através da institucionalização de esferas públicas competentes e capazes de provocar deliberações e tomadas de decisões pautadas pelo agir comunicativo é que se constituem processos democráticos e, portanto, uma gestão democrática da educação.

A partirdesse entendimento, podemos inferirque, no contexto educacional pernambucano, utilizam-se questionários, para traçar o perfil de estudantes e de servidores bem como avaliações, para 'medir' a aprendizagem dos alunos. Para conceber a gestão como um agir comunicativo, é necessário que a coordenação da ação comunicativa dentro da instituição ocorra de modo a possibilitar que os envolvidos se coloquem através do diálogo e do entendimento. Foi constatado nos documentos que todos os gestores escolares de Pernambuco assinam, no início do ano escolar, um termo de compromisso em que se comprometem a alcançar metas preestabelecidas para suas escolas (PERNAMBUCO, 2012d,2013, 2014). Desse modo, anulam-se as características próprias da esfera pública, onde a comunicação de temas, as tomadas de decisão, as opiniões, a sistematização e a condensação dos fluxos comunicacionais se convertem em opiniões públicas organizadas em temas específicos. Nesse sentido, "vislumbramos um modelo de gestão educacional que considera as potencialidades inerentes ao ser humano, voltadas para a comunicação e para a integração, criando oportunidades para que todos tenham direito de exercitar a fala, a crítica, a argumentação e de decidir sobre o projeto educativo institucional" (BRENNAND; BIZERRA, 2012, p. 22).

Nos documentos assinalados no item 2, buscamos identificar o modelo de democracia orientado para a gestão. Observamos que o modelo de democracia que prevalece nos achados é o liberal, porém de modo implícito, porque vimos, até aqui, que todos os processos de reforma educacional que houve em diversos países, inclusive no Brasil, foram influenciados pelos organismos internacionais característicos do contexto globalizado. E essas reformas surgiram para atender às 
necessidades do Estado Liberal. De acordo com a concepção liberal, o processo democrático tem a responsabilidade de projetar o Estado para atender aos interesses da sociedade. "De um lado, está o Estado como aparato da administração pública e, de outro lado, a sociedade organizada segundo as determinações do mercado" (BIZERRA, 2008, p. 120-121). De acordo com Habermas, o centro do modelo liberal não é a autodeterminação democrática de cidadãos deliberantes, mas sim, a normatização jurídico-estatal de uma sociedade econômica cuja tarefa é garantir um bem comum entendido de forma apolítica, pela satisfação das expectativas de felicidade de cidadãos produtivamente ativos. (HABERMAS, 2006b).

\section{O MODELO DE ACCOUNTABILITY IMPLANTADO}

De todos os grupos de documentos analisados, a categoria 'accountability' apresenta apenas uma ocorrência. Aparece com tradução literal como 'responsabilização'. Entretanto os mecanismos de controle apontados mostram claramente os mesmos do modelo e as diretrizes fazem referências às medidas tomadas pelo governo federal e pelos modelos já implantados em outros países e em estados brasileiros. Reforçam as palavras de Afonso (2009c, p. 64) de que a utilização de testes estandardizados, a crescente dependência das agências governamentais em relação à recolha e à análise de dados sobre o desempenho da escolas, a intensificação dos esforços para ligar a educação escolar às necessidades da indústria e a alteração nas expectativas em relação a avaliação educacional, são os resultados previsíveis desse movimento de globalização. Consta dos documentos que a escola deve voltar-se para atingir os objetivos do sistema de ensino. Parece ser levada a agir em mão dupla, pois, ao mesmo tempo em que elabora e põe em prática uma proposta pedagógica orientada para o desenvolvimento de cidadãos autodeterminados, atende aos interesses do Estado liberal em atingir resultados preestabelecidos. Essas constatações reforçam o pensamento de Afonso (2009c), quando afirma que modelos de responsabilização transformam-se em modelos tecnocráticos mais preocupados com os meios do que com os fins da educação. Partindo do entendimento de Afonso (2001, 2009a, 2009b, 2009b, 2010a, 2010b, 2010c, 2012) entendemos que o modelo de accountability, está associado às três dimensões - avaliação, responsabilização e prestação de contas.

A avaliação pode ser utilizada para diversos objetivos e funções. Nesse sentido, é condição sine qua non para o desenvolvimento de processos de prestação de contas e responsabilização (accountability). No entanto, deve-se verificar a que interesses serve e como é representada, pois é influenciada por forças políticas e tem efeitos políticos (AFONSO, 2009a, 2009c). A partir dos achados e tendo como referência o pensamento de Afonso (2009c) e Horta Neto (2010), podemos 
afirmar que o estado de Pernambuco tem um sistema próprio de avaliação - o SAEPE - e que o tipo de avaliação implantado é criterial ou somativo, com base em testes estardinandizados, porque a avaliação é vista como um indicador que pode ser aferido através de resultados quantificáveis, com matrizes curriculares pré-estabelecidas. Entendemos, também, que essas avaliações servem ao objetivo de coleta de informação sobre o sistema educativo do estado. Assim, através da avaliação criterial, podem estar sendo introduzidos efeitos de mercado no sistema educativo, utilizados como mecanismo de controle do Estado "[...] [e], por conseguinte [...] a centralização curricular" (AFONSO, 2009c, p. 36). Na tentativa de evitar essa situação, o estado de Pernambuco parece desenvolver ações voltadas àquelas escolas que por não atingirem as metas previstas "receberão reforço técnico, pedagógico e estrutural” (PERNAMBUCO, 2012d), com o objetivo de se reenquadrarem nos critérios pré-estabelecidos. Além das avaliações, aplica questionários aos alunos, aos professores e aos gestores a fim de traçar seu perfil socioeconômico. Horta Neto (2010) adverte que os fatores levantados nesses testes não influenciam os resultados dos estudantes, mas podem servir como fonte de informação para que o governo desenvolva ações voltadas à intervenção nas áreas prioritárias, visando a promover melhorias no ensino.

O modelo de accountability (responsabilização) implantado no sistema de gestão da rede obedece a parâmetros idealizados em outros países, como Portugal e EUA. Esse modelo é baseado em objetivos educacionais com metas pré-estabelecidas, sistema próprio de avaliação, política de incentivos e sistema de monitoramento. Outra inferência possibilitada pelos achados é que a responsabilização é feita depois de assinado o termo de compromisso, que coloca professores, gestores, alunos e suas famílias como responsáveis pelos resultados educacionais. Porém, esse termo é firmado e assinado apenas entre a Secretaria de Educação e os(as) diretores(as) escolares (Afonso, 2001, 2009a, 2009b, 2009c, 2010a, 2010b, 2010c, 2012). O diretor e/ou a escola são apontados como os principais responsáveis pelos resultados, enquanto o Estado apresenta-se como corresponsável. Isso mostra uma inversão de papéis, pois o Estado, como provedor ou garantidor do bem-estar social, é que deveria ser o principal responsável, e não, as escolas. É notório que o modelo de responsabilização (accountability) implantado ocorreu de forma impositiva através de leis e decretos.

Com base nos achados depreendemos que o modelo apresenta o pilar da prestação de contas tendo como base a transparência e a informação, porquanto são divulgados periodicamente boletins com informações sobre o sistema. Isso atesta o pensamento de Afonso (1999, 2001, 2009a, 2009b, 2009c, 2010a, 2010b, 2010c, 2012) e Shedler; Diamond; Platiner (1999), quando afirmam que a accountability é formada por três pilares: a responsabilização, a prestação de contas 
- em que a produção de informações, argumentações e justificações tem papel estruturante - e a avaliação, feita durante o processo de autoavaliação (ou avaliação ex-ante) e durante o processo de avaliação externa (ou avaliação ex-post).

Sobre essa questão, cabem algumas observações, já que o estado de Pernambuco afirma estar promovendo transparência e prestação de contas, ao informar à comunidade escolar e à sociedade em geral os resultados escolares. No entanto, essa atitude é questionável, pois não se promovem ações democráticas de gestão apenas com a publicização de resultados. É necessária a participação dessa comunidade nos momentos de deliberações e tomadas de decisões a respeito de seus anseios e suas necessidades e na elaboração dos objetivos educacionais, do currículo, da proposta pedagógica, enfim, do modelo de escola e, consequentemente, de educação que essa comunidade almeja. O Estado, através da Secretaria de Educação, coloca-se na posição de monitorar, o que, mais uma vez, fortalece o paradigma burocrático administrativo de Estado-regulador. Verificamos que, no sistema, são imputadas sansões ou recompensas para as escolas - e, consequentemente, para seus servidores - a partir dos resultados nas avaliações externas. Os servidores das escolas que alcançarem a partir de 50\% das metas previstas são compensados com bônus salarial. Além dessa premiação, são elaborados rankings escolares, em que são expostos os resultados das escolas a partir dos testes realizados. Afonso (2010b) chama atenção para a divulgação e os efeitos dos rankings escolares, pois, se eles podem ser interpretados no âmbito das escolas para fins pedagógicos, no sentido de melhorar o ensino, também entanto pressionam e reconfiguram as funções dos professores, visto que seu desempenho está associado aos resultados e às performances dos alunos.

\section{CONSIDERAÇÕES FINAIS}

A reforma empreendida no campo educacional desse estado tem como modelo as reformas empreendidas na década de 90 e defendidas, principalmente, por Bresser Pereira (2002, 2005, 2006a, 2006b, 2006c, 2007, 2013), de que o Estado deveria modificar, a burocracia estatal e adotar um modelo gerencial orientado para o atendimento dos cidadãos (clientes). A gestão da rede de ensino básico adota o modelo de gestão por resultados, tendo como base o planejamento estratégico, a responsabilização e o monitoramento (controle), evidenciando a quase ausência do entendimento de que a escola é uma esfera pública formal, capaz de produzir espaços de fala e construção de consensos pela via do entendimento.

O modelo de democracia que prevalece no sistema é o liberal, apesar de ser possível registrar uma preocupação com a implantação de processos democráticos, no entanto, eles ainda são insuficientes e estão restritos ao 
ambiente escolar. A rede de ensino tem um sistema próprio de avaliação - Sistema de Informações de Educação em Pernambuco (SAEPE) - e o tipo de avaliação implantado em seu sistema educacional é o criterial ou somativo, com base em testes estandardizados. A avaliação também é vista como um indicador que pode ser aferido mediante resultados quantificáveis, através de matrizes curriculares préestabelecidas, e serve ao objetivo de coletar informações sobre o sistema educativo do Estado. O modelo de responsabilização (accountability) implantado no sistema da rede apresenta o pilar da prestação de contas, cuja base são a transparência e a informação, pois periodicamente são divulgados boletins com informações sobre o sistema educacional e os rankings escolares em que são expostos os resultados das escolas a partir dos testes realizados. Nesse sistema, são imputadas sansões ou oferecidas recompensas às escolas - $\mathrm{e}$, consequentemente, a seus servidores - de acordo com os resultados nas avaliações externas.

Por fim, alertamos, para a forma e o conteúdo das reformas empreendidas na gestão educacional no geral. Pois, de acordo Diane Ravitch (2011) as atuais reformas colocam a educação pública em perigo. A autora, ao rever suas posições quanto às reformas educacionais admite que as soluções de mercado não estão alcançando as melhorias esperadas no desempenho dos alunos. $\mathrm{O}$ foco das atuais reformas restringe-se à responsabilização baseada em testes, ignorando preocupações essenciais sobre qual educação se espera e como fazer para melhorar as escolas públicas que enfrentam dificuldades. Ao invés de lidar com esses problemas espinhosos, parece mais fácil entregar a administração das escolas à iniciativa privada, sob o argumento de que ela fará melhor do que a administração pública, engessada e ineficaz.

É importante assinalar que o estudo apresenta achados que precisam de aprofundamento que podem ser realizados em estudos futuros. Apresenta limitações em função da necessidade de abarcar outras análises de dimensões a serem exploradas, da grande quantidade de documentos disponíveis e do tempo necessário para analisá-los.

\section{REFERÊNCIAS}

AFONSO, Almerindo Janela.. Para uma conceitualização alternativa de accountability em educação. Educ. Soc., Campinas,v. 33, n. 119, p. 471-484, jun. 2012.

Políticas educativas e autoavaliação da escola pública portuguesa: apontamentos de uma experiência. Estudos em avaliação educacional, São Paulo, v. 21, n. 46, p. 343-362, 2010a. 
Gestão, autonomia e accountability na escola pública portuguesa: breve diacronia. Revista Brasileira de Política e Administração da Educação. Porto Alegre, v. 26, n. 1, p. 13-30, 2010b.

Um olhar sociológico da accountability em Educação. In: ESTEBAN, Maria Teresa; AFONSO, Almerindo Janela (orgs.). Olhares e interfaces: reflexões críticas sobre a avaliação. São Paulo, Cortez: 2010c.

AFONSO, Almerindo Janela. Políticas avaliativas e accountability em educação: subsídios para um debate iberoamericano. Sísifo: Revista de Ciências da Educação, Lisboa, n. 9, p. 57-70. 2009a.

. Nem tudo o que conta é mensurável ou comparável: crítica à accountability baseada em testes estandardizados e rankings escolares. Revista Lusófona de Educação, Lisboa, n. 13, p. 13-29, jul. 2009b.

Avaliação educacional: regulação e emancipação. $4^{a}$ Edição, São Paulo: Cortez, 2009c. avaliação

Reforma do Estado e políticas educacionais: entre a crise do Estadonação e a emergência da regulação supranacional. Educ. Soc. Campinas, v. 22, n. 75, p. 15-32, ago.2001.

Estado, mercado, comunidade e avaliação: esboço para uma rearticulação crítica. Educação \& Sociedade,Campinas,Ano XX, n. 69, p. 139-164, Dez. 1999.

ANDRADE, Dalton Francisco de; TAVARES, Heliton Ribeiro; VALLE, Raquel da Cunha. Teoria da Resposta ao Item: conceitos e aplicações. SINAPE, 2000. Disponível em: http://egov.ufsc.br/portal/sites/default/files/livrotri.pdf . Acesso em: 18 abril 2015.

BIZERRA, Maria da Conceição. Gestão educacional: fusão de horizontes da democracia liberal à democracia procedimental. João Pessoa: UFPB, 2008. 219 f. Tese (Doutorado em Educação) - Universidade Federal da Paraíba, João Pessoa, 2008.

BRASIL. Ideb - Apresentação. Disponível em: http://portal.mec.gov.br/index. php?option $=$ com_content\&view $=$ article\&id $=180 \& I t e m i d=336$. Acesso em: 18 Abri 2015a. 
. SAEB. Disponível em: http://portal.inep.gov.br/web/saeb/aneb-eanresc. Acesso em 18 Abri 2015b.

BRENNAND, Edna Gusmão de Góis; BIZERRA, Maria da Conceição. A gestão democrática como equilíbrio entre a razão e a vontade autônoma. In: BRENNAND, Edna Gusmão de Góis; VIRGİNIO, Maria Helena da Silva. Gestão, aprendizagem e currículo como processo social. João Pessoa: UFPB, 2012 .

BRESSER PEREIRA, Luiz Carlos. Globalização e Estado-Nação. Escola de Economia de São Paulo. Textos para discussão. n. 327, Ago. 2013a.

BRESSER PEREIRA, Luiz Carlos. O Estado Brasileiro Diante da Globalização e da Preferencia pelo Consumo imediato. Escola de Economia de São Paulo. Textos Para Discussão, n. 327, agosto de 2013b: 1-17.

- Gestão do Setor Público: estratégia e estrutura para um novo Estado. In: BRESSER PEREIRA, Luiz Carlos e SPINK, Peter (orgs.). Reforma do Estado e administração pública gerencial. Tradução de Carolina Andrade. Editora Fundação Getúlio Vargas, Rio de Janeiro, 2006b.

. Da Administração Pública à Gerencial. In:BRESSER PEREIRA, Luiz Carlos; SPINK, Peter (orgs.). Reforma do Estado e administração pública gerencial. Tradução de Carolina Andrade. Editora Fundação Getúlio Vargas, Rio de Janeiro, 2006c.

BRESSER PEREIRA, Luiz Carlos. Democracia republicana e participativa. Novos Estudos Cebrap, 71, março 2005: 77-91.

. Reforma da nova gestão pública: agora na agenda da América Latina, no entanto ...Revista do Serviço Público. Ano 53, jan-mar 2002.

. Do Estado Patrimonial ao Gerencial. In: PINHEIRO, Wilheim e Sachs (orgs.). Brasil: Um Século de Transformações. São Paulo: Cia. das Letras, 2001.

; SPINK, Peter (orgs.). Reforma do Estado e administração pública gerencial. Tradução de Carolina Andrade. Editora Fundação Getúlio Vargas, Rio de Janeiro, 2006a. 
BROOKE, Nigel. O futuro das políticas de responsabilização educacional no Brasil. Cad. Pesqui.,São Paulo ,v. 36, n. 128, p. 377-401, ago. 2006.

CASTRO, Alda Maria Duarte Araújo. Accountability: uma nova estratégia de controle da gestão escolar. In: Conferência Internacional - Educação, globalização e cidadania: novas perspectivas da Sociologia da Educação, 2008, João Pessoa.

HABERMAS, Jürgen. A inclusão do outro: estudos de teoria política. Trad. George Sperber, Paulo Asthor Soethe. São Paulo: Loyola, 2002.

Direito e democracia: entre facticidade e validade, vol. I. Tradução Flávio Beno Siebeneichler. Rio de Janeiro: Tempo Brasileiro, 1997a.

HABERMAS, Jürgen. Direito e democracia: entre facticidade e validade, vol. II. Tradução Flávio BenoSiebeneichler. Rio de Janeiro: Tempo Brasileiro, 1997b.

A crise de legitimação do capitalismo tardio. Tradução de Vamireh Chacon. Rio de Janeiro. Edição Tempo Brasileiro. 1980.

HORTA NETO, João Luiz. Avaliação externa de escolas e sistemas: questões presentes no debate sobre o tema. Revista Brasileira Estudos Pedagógicos, Brasília, v. 91, n. 227, p. 84-104, jan./abr. 2010.

Um olhar retrospectivo sobre a avaliação externa no Brasil: das primeiras medições em educação até o SAEB de 2005. Revista Iberoamericana de Educación,n. 42/5, 25 de abril de 2007.

IANNI, Otavio. Teorias da globalização. $9^{\mathrm{a}}$ ed. Civilização Brasileira. Rio de janeiro: 2001.

OCDE. Sobre o Pisa. Disponível em: http://www.oecd.org/pisa/aboutpisa . Acessado em 02/01/2015a.

Sobre a OCDE. Disponível em: http://www.oecd.org/about/ . Acessado em 02/01/2015b.

PERNAMBUCO. As mudanças Educacionais em Pernambuco: 2007/2014; .[ 2015a?] (cartilha) 
. The educational changes in Pernambuco - Brazil: 2007/2014. .[ 2015b?] Nota 1 - DVD

. Balanço da Educação 2014. . [ 2015c?] (Cartilha).

Slides da apresentação do Programa de Modernização da Gestão Pública - Metas para a Educação. 2014 (Arquivo da Secretaria de Educação do Estado de Pernambuco).

PERNAMBUCO. / SEEP Resultado IDEPE 2012. Disponível em: http:// www.educacao.pe.gov.br/portal/?pag=1\&cat=37\&art=1351 . Acessado em 25/07/2013.

. Resultado IDEPE 2013. Disponível em: http://http://www.educacao. pe.gov.br/portal/?pag=1\&cat=37\&art=1973 . Acessado em: 10/03/2015.

. Curso de Aperfeiçoamento em Gestão Escolar: Módulo I - Políticas públicas educacionais: marcos regulamentatórios. Recife: Secretaria de Educação do Estado do Pernambuco, 2012a.

. Curso de Aperfeiçoamento em Gestão Escolar: Módulo VII - Educação de qualidade social. Recife: Secretaria de Educação do Estado do Pernambuco, 2012b.

Curso de Aperfeiçoamento em Gestão Escolar: Módulo XI Monitoramento e avaliação dos processos de ensino e aprendizagem. Recife: Secretaria de Educação do Estado do Pernambuco, 2012c.

. Curso de Aperfeiçoamento em Gestão Escolar: Módulo XII - Políticas de Responsabilização Educacional. Recife: Secretaria de Educação do Estado do Pernambuco, 2012d.

. Nota técnica - A avaliação das escolas estaduais e o bônus de desempenho educacional (BDE). 2011. Apresenta as diretrizes de avaliação das escolas e do BDE. Disponível http://www.siepe.educacao.pe.gov.br

Avanços na Educação de Pernambuco: janeiro/2007 - março/2010. [ 2011?]. Cartilha) 
Decreto $\mathrm{n}^{\mathrm{o}}$ 33.711, de 28 de julho de 2009. Dispõe sobre o pagamento do Bônus de Desempenho Educacional - BDE, e dá outras providências. Disponível em: http://www.siepe.educacao.pe.gov.br/WebModuleSme/ itemMenuPaginaConteudoUsuarioAction.do.

Educação. 2008.

\section{Programa de Modernização da Gestão Pública - Metas para a}

Lei n. 13.486 de $1^{\circ}$ de julho de 2008a. Disponível em: http:/ / www.siepe. educacao.pe.gov.br/WebModuleSme/itemMenuPaginaConteudoUsuarioAction. do? actionType $=$ mostrar\&idPaginaItemMenuConteudo $=5913$. Acessado em 08 de agosto de 2013.

Decreto $\mathrm{n}^{\circ} \mathbf{3 2 . 3 0 0}$, de 08 de setembro de 2008b. Regulamenta a Lei $\mathrm{n}^{\circ}$ 13.486 , de $1^{\circ}$ de julho de 2008, que institui o Bônus de Desempenho Educacional - BDE, no âmbito do estado de Pernambuco, e dá outras providências. Disponível em: http://www.siepe.educacao.pe.gov.br/WebModuleSme/ itemMenuPaginaConteudoUsuarioAction.do?action Type $=$ mostrar\&idPaginaIte mMenuConteudo $=5913$

. Lei n. 13.696 de 18 de dezembro de 2008c. Disponível em: http://www.siepe.educacao.pe.gov.br/WebModuleSme/ itemMenuPaginaConteudoUsuarioAction.do?actionType $=$ mostrar\&idPaginaIte mMenuConteudo=5913. Acessado em 08 de agosto de 2013.

2008d. (cartilha).

Modernização da Gestão Pública da educação de Pernambuco.

Lei n $^{\circ}$ 13.273, de 05 de julho de 2007. Disponível em: http:/ / www.siepe. educacao.pe.gov.br/WebModuleSme/itemMenuPaginaConteudoUsuarioAction. do?actionType $=$ mostrar\&idPaginaItemMenuConteudo $=5905$. Acessado em: 08 de agosto de 2013.

Lei $\mathrm{n}^{\mathbf{0}}$ 12.252, de 08 de julho de 2002. Aprova o Plano Estadual de Educação e dá outras providências.

RAVITCH, Diane. Vida e Morte do Grande Sistema Escolar Americano: como os testes padronizados e o modelo de mercado ameaçam a educação. Porto Alegre: Sulina, 2011. 
SCHEDLER, Andreas; DIAMOND, Lary; PLATTNER, Marc F. The self restraining State: accountability in new democracies. United States, 1999.

PROCIANA FERREIRA DA SILVA é Mestre em Gestão nas Organizações Aprendentes - MPGOA pela Universidade Federal da Paraíba - UFPB; Graduada em História pela Universidade Regional do Cariri - URCA; Especialista em História e Sociologia Universidade Regional do Cariri - URCA; e membro do Grupo de Pesquisa Cultura Digital e Educação, Linha de Pesquisa Gestão de Projetos Educativos e Tecnologias Emergentes do Conselho Nacional de Desenvolvimento Científico e Tecnológico (CNPq). Atua como gestora escolar na rede estadual de educação do Estado de Pernambuco e como professora no ensino superior na rede privada de ensino. E-mail: prociana12@gmail.com

EDNA GUSMÃO DE GÓIS BRENNAND é Pós-doutora pela Universidade de Louvain - UCL, Bélgica e Universidade Lusófona de Humanidades e TecnologiasULHT, Portugal; Doutora em Sociologia pela Sorbonne, França; Professora PPGE/MPGOA/Universidade Federal da Paraíba - Brasil. E-mail: ebrenna2@ uol.com.br 